Editorial

\title{
Fertility sparing approach in young patients with early stage cervical cancer
}

Volume 6 Issue 2 - 2017

\section{Editorial}

Cervical cancer (CC) represents the fourth most common malignancy in women worldwide, after breast, colorectal and lung cancer. ${ }^{1,2}$ The disease mainly affects young women at the reproductive age and is more common in developing countries, where $\mathrm{CC}$ accounts for approximately $12 \%$ of all female cancers. ${ }^{12}$ Furthermore, the mortality rate in developing countries is 10-14 times higher than in developed ones. ${ }^{1,2}$

According to the recommendations of many international scientific societies, $\mathrm{CC}$ treatment depends on disease stage and consists of surgery, radiotherapy or combination of radiotherapy and chemotherapy. ${ }^{3-5}$ However, the extent of surgery should be carefully individualized based on the disease stage, the patient's general medical status and the desire of fertility preservation. ${ }^{3,4,6}$

In this light, fertility sparing treatment should be offered in young patients with early stage disease and strong desire for fertility preservation. ${ }^{3,4,6,7}$ This is the reason why, recent guidelines incorporate conservative surgical treatment options in well selected patients after extensive counseling regarding risks for recurrence, anticipated future fertility, pregnancy issues and perinatal outcomes..$^{3,6-8}$ Nevertheless, patients with aggressive (small cell neuroendocrine carcinoma) or potentially aggressive (gastric type adenocarcinoma, minimal deviation adenocarcinoma) histologic subtypes, are not eligible for fertility sparing management. ${ }^{3,9,10}$

In CC patients with FIGO stage IA1 disease (stromal invasion of $\leq 3.0 \mathrm{~mm}$ in depth and extension of $\leq 7.0 \mathrm{~mm}$ ) and no lymphovascular space invasion (LVSI), the risk of lymph node metastasis is almost $0.8 \%$ and the risk of recurrence is about $0.6 \% .{ }^{11-14}$ Those patients are eligible for conservative management with cervical conization only. ${ }^{3,4,6,15-17}$ The cone should have at least $3 \mathrm{~mm}$ clear margins for invasive disease or high-grade squamous intraepithelial lesion (HSIL). ${ }^{3,4}$ Moreover, both the ectocervix and endocervical canal should be excised in a single specimen. ${ }^{3,4}$ For the procedure, cold knife conisation (CKC) is usually preferred, because it provides several advantages; especially in the evaluation of marginal involvement. ${ }^{18}$ If loop electrosurgical excision procedure (LEEP) is used, then additional care to minimize the electrosurgical effect in specimen's margins should be taken. ${ }^{18,19}$ In case of positive cone margins, either the procedure should be repeated or a radical trachelectomy should be performed. ${ }^{3}$

In CC patients with FIGO stage IA1 disease and LVSI, the risk of lymph node metastasis is nearly $8.2 \%$ and the risk of recurrence is approximately $3.1 \% .{ }^{12-14}$ In those patients, either cervical conization or radical trachelectomy, with additional pelvic lymphadenectomy +/- para-aortic lymph node sampling should be performed. ${ }^{3,4,6,16,17,20-22}$ Particularly for patients with positive cone margins, either the conization procedure should be repeated or radical trachelectomy should be performed. ${ }^{3,21,22}$

On the other hand, in FIGO stage IA2 patients (stromal invasion between 3.0 and $5.0 \mathrm{~mm}$ in depth and extension of $\leq 7.0 \mathrm{~mm}$ ), the risk

\author{
Georgios Androutsopoulos,' loannis C \\ Kotsopoulos,' Georgios Michail,' Georgios \\ Decavalas ${ }^{2}$ \\ 'Department of Obstetrics and Gynecology, University of \\ Patras, Greece \\ ${ }^{2}$ Queen Elizabeth Hospital, Gateshead, United Kingdom
}

\begin{abstract}
Correspondence: Georgios Androutsopoulos, Assistant Professor, Department of Obstetrics and Gynecology, University of Patras, Medical School, Rion 26504, Greece, Tel 306974088092,Email androutsopoulos@upatras.gr, androusopoulosgeorgios@hotmail.com
\end{abstract}

Received: January 29, 2017 | Published: February 16, 2017

of lymph node metastasis is almost $8 \%$ and the risk of recurrence is substantially higher in patients with LVSI $(15.7 \%$ vs $1.7 \%){ }^{11,12,14,23}$ Those patients are eligible for fertility sparing management with radical trachelectomy, pelvic lymphadenectomy +/- paraaortic lymph node sampling. 3,4,6,8,21,24,25 Apart from that, cervical conization with additional pelvic lymphadenectomy +/- paraaortic lymph node sampling represents an alternative treatment choice, particularly in CC patients with stage IA2 disease, negative cone margins and negative lymph nodes. ${ }^{3,4,6,17,20,21}$

Likewise, in CC patients with FIGO stage IB1disease (clinically visible lesion $\leq 4.0 \mathrm{~cm}$ in greatest dimension), the risk of lymph node metastasis is about $14.9 \%$ and the risk of recurrence is significantly higher. ${ }^{11,26}$ Additionally, tumor size greater than $2 \mathrm{~cm}$, deep stromal invasion (greater than $50 \%$ in depth) and LVSI, are negative prognostic factors. ${ }^{24,25}$ Patients with tumor size up to $2 \mathrm{~cm}$, are eligible for fertility sparing management with radical trachelectomy, pelvic lymphadenectomy +/- paraaortic lymph node sampling. $3 ., 4,6,8,21,24,25,27$ In those patients, radical trachelectomy could be performed either vaginally or abdominally, with no significant differences in long-term oncologic outcome..$^{28}$

The procedure of vaginal radical trachelectomy was first described by Dargent ${ }^{29}$ and, in terms of surgical technique, shares many similarities with the type B radical hysterectomy. ${ }^{3,29-31}$ In particular, the cervix, the upper $1-2 \mathrm{~cm}$ of vagina and the supporting ligaments are being excised. ${ }^{3,30}$ Moreover, pelvic lymphadenectomy $+/$ - paraaortic lymph node sampling are performed laparoscopically. ${ }^{30}$ It is worth noting that vaginal radical trachelectomy should be used in well selected young CC patients with FIGOstage IA1 (with LVSI), IA2 and IB1 (with tumor size up to $2 \mathrm{~cm}$ ) disease. . $22,27,32^{2}$

In contrast, abdominal radical trachelectomy provides a wider resection of parametria and represents a less conservative alternative, compared with vaginal radical trachelectomy. ${ }^{3,25,27,33,34}$ The procedure has many similarities with the type $\mathrm{C}$ radical hysterectomy, regarding surgical technique and oncologic outcome. ${ }^{3,25,31,33,35}$ The cervix, the upper $1-2 \mathrm{~cm}$ of vagina, the parametrium and the paracolpos are 
being resected. ${ }^{3,33,36}$ It is interesting to note, that abdominal radical trachelectomy may be used in well selected young $\mathrm{CC}$ patients with FIGO stage IA1 (with LVSI), IA2 and IB1 (with tumor size up to $2 \mathrm{~cm}$ ) disease. ${ }^{3,22,27}$ However, recent studies evaluating the oncologic outcome of abdominal radical trachelectomy in CC patients with FIGO stage IB1 disease and tumor size between 2 and $4 \mathrm{~cm}$, have shown promising results..$^{35,36}$

The abdominal radical trachelectomy can be performed either with the standard or the minimal invasive approach (laparoscopy, robotic assisted surgery). ${ }^{37-39}$ The minimal invasive approach, offers many advantages in terms of recovery, blood loss and total hospital stay, while there is no compromise in the oncologic outcome. . $37-39^{3}$

Additionally, the implementation of sentinel lymph node mapping and dissection is feasible in CC patients with early stage disease and decreases significantly the morbidity of systematic lymphadenectomy without affecting survival. ${ }^{40,41}$ The utilization of ultrastaging plays a crucial role in the detection of micro metastases in dissected lymph nodes. ${ }^{40,42}$ The procedure of sentinel lymph node mapping and dissection should be performed bilaterally, because it provides more reliable data regarding the sentinel lymph node metastases. ${ }^{40,41}$

In general, fertility outcomes are better in $\mathrm{CC}$ patients treated with vaginal radical trachelectomy, when compared with others treated with the abdominal approach. ${ }^{22,27}$ This is mainly because the latter represents a less conservative approach. ${ }^{25,27,33,34}$ However, there is a wide variation in pregnancy rates among patients treated either with vaginal or abdominal radical trachelectomy. ${ }^{22,27,28,32,43-45}$ Furthermore, there is increased risk for miscarriages and preterm labors in both patient groups, mainly because of the impaired cervical function. ${ }^{3,22,27,28,43,44}$

In conclusion, fertility sparing treatment is feasible in well selected young CC patients with early stage disease and strong desire for fertility preservation. ${ }^{3,46}$ However, all patients should have an adequate pretreatment assessment as well as a thorough counseling regarding risk for recurrence, future fertility, pregnancy issues and perinatal outcomes. ${ }^{8}$

\section{Acknowledgments}

None.

\section{Conflicts of interest}

None.

\section{References}

1. WHO. Estimated cancer incidence, mortality and prevalence worldwide in 2012. GLOBOCAN. 2012

2. Ferlay J, Soerjomataram I, Dikshit R, et al. Cancer incidence and mortality worldwide: sources, methods and major patterns in GLOBOCAN 2012. Int J Cancer. 2015;136(5):E359-E386.

3. NCCN. Clinical Practice Guidelines in Oncology: Cervical Cancer NCCN.org. 2017.

4. Colombo N, Carinelli S, Colombo A, et al. Cervical cancer: ESMO Clinical Practice Guidelines for diagnosis, treatment and follow-up. Ann Oncol. 2012;23(Suppl 7):vii27- vii32.

5. ESGO. Algorithms for management of cervical cancer. ESGO.org. 2010.

6. Chuang L, Temin S, Berek J. Management and care of women with invasive cervical cancer: American Society of Clinical Oncology Resource-Stratified Clinical Practice Guideline Summary. J Oncol
Pract. 2016;12(7):693-696.

7. Bentivegna E, Gouy S, Maulard A, et al. Oncological outcomes after fertility-sparing surgery for cervical cancer a systematic review. Lancet Oncol. 2016;17(6):e240-e53.

8. Ramirez P, Pareja R, Rendon G, et al. Management of low-risk earlystage cervical cancer should conization, simple trachelectomy or simple hysterectomy replace radical surgery as the new standard of care? Gynecol Oncol. 2014;132(1):254-259.

9. Viswanathan A, Deavers M, Jhingran A, et al. Small cell neuroendocrine carcinoma of the cervix outcome and patterns of recurrence Gynecol Oncol. 2004;93(1):27-33.

10. Young R, Clement P. Endocervical adenocarcinoma and its variants their morphology and differential diagnosis Histopathology. 2002;41(3):185207.

11. Pecorelli S. Revised FIGO staging for carcinoma of the vulva, cervix, and endometrium. Int J Gynaecol Obstet. 2009;105(2):103-104.

12. Benedet J, Anderson G. Stage IA carcinoma of the cervix revisited. Obstet Gynecol. 1996;87(6):1052-1059.

13. Ostor A. Pandora's box or Ariadne's thread? Definition and prognostic significance of microinvasion in the uterine cervix Squamous lesions Pathol Annu. 1995;30(Pt 2):103-136.

14. Mota F. Microinvasive squamous carcinoma of the cervix treatment modalities Acta Obstet Gynecol Scand. 2003;82(6):505-509.

15. Sevin BU, Nadji M, Averette He, et al. Microinvasive carcinoma of the cervix Cancer. 1992;70(8):2121-2128.

16. Wright J, NathavithArana R, Lewin S, et al. Fertility-conserving surgery for young women with stage IA1 cervical cancer safety and access. Obstet Gynecol. 2010;115(3):585-590.

17. Winter R. Conservative surgery for microinvasive carcinoma of the cervix. J Obstet Gynaecol Res. 1998;24(6):433-436.

18. Miroshnichenko GG, Parva M, Holtz DO, et al. Interpretability of excisional biopsies of the cervix cone biopsy and loop excision. J Low Genit Tract Dis. 2009;13(1):10-12.

19. Kim MK, Kim MA, Kim JW, et al. Loop electrosurgical excision procedure findings for identification of patients with early-stage cervical cancer suitable for less radical surgery. Int J Gynecol Cancer. 2012;22(7):1214-1219.

20. Yoneda JY, Braganca JF, Sarian LO, et al. Surgical treatment of microinvasive cervical cancer analysis of pathologic features with implications on radicality. Int J Gynecol Cancer. 2015;25(4):694-698.

21. Abu-Rustum NR, Sonoda Y. Fertility-sparing surgery in early-stage cervical cancer indications and applications. J Natl Compr Canc Netw. 2010;8(12):1435-1438.

22. Plante M, Gregoire J, Renaud $\mathrm{MC}$, et al. The vaginal radical trachelectomy an update of a series of 125 cases and 106 pregnancies. Gynecol Oncol. 2011;121(2):290-297.

23. Buckley S, Tritz D, Van Le L, et al. Lymph node metastases and prognosis in patients with stage IA2 cervical cancer. Gynecol Oncol. 1996;63(1):4-9.

24. Park JY, Joo WD, Chang SJ, et al. Long-term outcomes after fertilitysparing laparoscopic radical trachelectomy in young women with earlystage cervical cancer an Asan Gynecologic Cancer Group (AGCG) study. J Surg Oncol. 2014;110(3):252-257.

25. Diaz JP, Sonoda Y, Leitao MM, et al. Oncologic outcome of fertilitysparing radical trachelectomy versus radical hysterectomy for stage IB1 cervical carcinoma. Gynecol Oncol. 2008;111(2):255-260. 
26. Chandacham A, Charoenkwan K, Siriaunkgul S, et al. Extent of lymphovascular space invasion and risk of pelvic lymph node metastases in stage IB1 cervical cancer. J Med Assoc Thai. 2005;88(Suppl 2):S31S36.

27. Cao DY, Yang JX, Wu XH, et al. Comparisons of vaginal and abdominal radical trachelectomy for early-stage cervical cancer preliminary results of a multi-center research in China. Br J Cancer. 2013;109(11):27782782 .

28. Schneider A, Erdemoglu E, Chiantera V, et al. Clinical recommendation radical trachelectomy for fertility preservation in patients with earlystage cervical cancer. Int J Gynecol Cancer. 2012;22(4):659-666.

29. Dargent D, Brun J, Roy M, et al. La trachelectomieelargie (TE), une alternative a l' hysterectomieradicaledans le traitement des cancers infiltrants developpes sur la face externe du col uterin. $J O B G Y N$ 1994;2:285-292.

30. Dargent D, Martin X, Sacchetoni A, et al. Laparoscopic vaginal radical trachelectomy a treatment to preserve the fertility of cervical carcinoma patients. Cancer. 2000;88(8):1877-1882.

31. Cibula D, Abu-Rustum NR, Benedetti-Panici P, et al. New classification system of radical hysterectomy emphasis on a three-dimensional anatomic template for parametrial resection. Gynecol Oncol. 2011;122(2):264-268.

32. Hauerberg L, Hogdall C, Loft A, et al. Vaginal Radical Trachelectomy for early stage cervical cancer Results of the Danish National Single Center Strategy. Gynecol Oncol. 2015;138(2):304-310.

33. Abu-Rustum NR, Sonoda Y, Black D, et al. Fertility-sparing radical abdominal trachelectomy for cervical carcinoma technique and review of the literature. Gynecol Oncol. 2006;103(3):807-813.

34. Einstein M, Park K, Sonoda Y, et al. Radical vaginal versus abdominal trachelectomy for stage IB1 cervical cancer a comparison of surgical and pathologic outcomes. Gynecol Oncol. 2009;112(1):73-77.

35. Wethington S, Sonoda Y, Park K, et al. Expanding the indications for radical trachelectomy a report on 29 patients with stage IB1 tumors measuring 2 to 4 centimeters. Int J Gynecol Cancer. 2013;23(6):10921098 .
36. Lintner B, Saso S, Tarnai L, et al. Use of abdominal radical trachelectomy to treat cervical cancer greater than $2 \mathrm{~cm}$ in diameter. Int $J$ Gynecol Cancer. 2013;23(6):1065-1070.

37. Kucukmetin A, Biliatis I, Ratnavelu N, et al. Laparoscopic radical trachelectomy is an alternative to laparotomy with improved perioperative outcomes in patients with early-stage cervical cancer. Int J Gynecol Cancer. 2014;24(1):135-140.

38. Johansen $\mathrm{G}$, Lonnerfors $\mathrm{C}$, Falconer $\mathrm{H}$, et al. Reproductive and oncologic outcome following robot-assisted laparoscopic radical trachelectomy for early stage cervical cancer Gynecol Oncol. 2016;141(1):160-165.

39. Vieira M, Rendon G, Munsell M, et al. Radical trachelectomy in earlystage cervical cancer A comparison of laparotomy and minimally invasive surgery. Gynecol Oncol. 2015;138(3):585-589.

40. Cormier B, Diaz JP, Shih K, et al. Establishing a sentinel lymph node mapping algorithm for the treatment of early cervical cancer. Gynecol Oncol. 2011;122(2):275-280.

41. Lecuru F, Mathevet P, Querleu D, et al. Bilateral negative sentinel nodes accurately predict absence of lymph node metastasis in early cervical cancer results of the SENTICOL study. J Clin Oncol. 2011;29(13):16861691.

42. Cibula D, Abu-Rustum NR, Dusek L, et al. Bilateral ultrastaging of sentinel lymph node in cervical cancer Lowering the false-negative rate and improving the detection of micrometastasis. Gynecol Oncol. 2012;127(3):462-466

43. Kasuga Y, Nishio H, Miyakoshi K, et al. Pregnancy Outcomes After Abdominal Radical Trachelectomy for Early-Stage Cervical Cancer A 13-Year Experience in a Single Tertiary-Care Center. Int J Gynecol Cancer. 2016;26(1):163-168.

44. Speiser D, Kohler C, Schneider A, et al. Radical vaginal trachelectomy a fertility-preserving procedure in early cervical cancer in young women. Dtsch Arztebl Int. 2013;110(17):289-295.

45. Willows K, Lennox G, Covens A. Fertility-sparing management in cervical cancer balancing oncologic outcomes with reproductive success. Gynecol Oncol Res Pract. 2016;3:9. 